\title{
Rapid transit service in the unique context of Holy Makkah: assessing the first year of operation during the 2010 pilgrimage season
}

\author{
I. Kaysi ${ }^{1}$, M. Sayour ${ }^{2}$, B. Alshalalfah ${ }^{2}$ \& A. Gutub ${ }^{3}$ \\ ${ }^{1}$ American University of Beirut, Lebanon \\ ${ }^{2}$ SETS sarl, Lebanon \\ ${ }^{3}$ Center of Research Excellence in Hajj and Omrah, \\ Umm Al-Qura University, KSA
}

\begin{abstract}
Each year, more than 2 million Muslims from around the world gather in the City of Makkah in Saudi Arabia to perform the annual pilgrimage. A significant milestone in the effort to improve the existing transport system in the Holy City has been the introduction of the Southern Masha'er Rail Line (SMR) during the 2010 pilgrimage season. The line was designed to accommodate the unusual demand and specific movement patterns during the pilgrimage season. In its first year of operation, the line was supposed to operate at only $35 \%$ of its full capacity, before full implementation in the following year when the line was expected to transport 72,000 passengers per hour. This paper presents the results of a study to assess the performance of the rail line in its first year of operation. The analysis revealed that the majority of pilgrims found the rail line and its stations to be of excellent quality and exceeded their expectations. However, the analysis also revealed that the rail system suffered from operational and scheduling adherence problems that resulted in fluctuations in service frequency, capacity utilization rates, and cases of long waiting times. This paper concludes with recommendations for future improvements to the rail system based on the results of this evaluation study.
\end{abstract}

Keywords: pilgrimage season, controlled demand, specific rail movements. 


\section{Introduction}

For a period of several days each year, more than two million Muslim pilgrims from around the world travel to the City of Makkah in Saudi Arabia to perform Pilgrimage (aka Hajj), one of the five pillars of Islam. The year $2010(1431 \mathrm{H})$ was no exception, as it drew 2.8 million pilgrims from around the world to the Holy City and the surrounding area of the Holy Sites (aka Al-Masha'er AlMugadassah). This number is expected to grow rapidly in future years as a result of several social and economic factors. This is expected to add more congestion and create bigger crowds on the streets of Makkah and the Holy Sites, which are already suffering from extreme traffic congestion and pedestrian overcrowding during the pilgrimage season. The Saudi Arabian authorities are trying to address this unique situation by undertaking several measures that aim at improving the transportation system and upgrading the infrastructure of Makkah and its surroundings. A significant milestone of this effort to improve the existing transportation conditions has been the introduction of a new and untraditional transport mode, namely the Southern Masha'er Rail Line (SMR).

The rail line was introduced during the 2010 pilgrimage season as an additional transport mode in the Holy Sites area to supplement the traditional modes of transportation that have been used in the area such as walking, cars, and buses. In its first year of operation, the line operated at partial capacity, with a plan to operate the line at full capacity during the 2011 Pilgrimage season. A performance study was needed in order to assess the performance of the system and how well it is meeting the stakeholders' objectives during its first year of operation; this assessment would then help determine the extent to which the system should be expanded. Accordingly, this paper presents the results of this performance assessment study that was conducted using data collected during the 2010 pilgrimage season. The paper is structured as follows: section 2 elaborates on the rail line characteristics for a better understanding of the framework of the study and the unique operation of the line. The data collection plan, including the pilgrim surveys, the travel diaries and GPS data collected by the students is presented in section 3, while the results obtained and their analysis are described in section 4 . Section 5 concludes with recommendations on how to improve the rail line in future years.

\section{Literature review}

At full capacity, the SMR line is expected to transport 72,000 pilgrims per hour, making it one of the highest capacity rapid transit lines in the world. Given that this line was introduced to serve people during a specific event in which millions of people gather at the same place for a short period of time, it is important therefore to first look at how other places around the world have handled or are planning to handle similar crowded events, starting with the Olympic Games that will be held in London in the summer of 2012, attracting millions of athletes, spectators and tourists. At the transportation system level, the Olympic Park will be served by a dedicated rail shuttle service, called the Olympic 'Javelin', which 
is designed to transport 25,000 spectators per hour. Moreover, at Stratford Regional Station, one of the busiest interchanges outside Central London with approximately 37,000 passengers travelling through the station during an average three hour morning peak period, upgrades are planned to increase the station's capacity during the same three hour peak period to accommodate growing demand and the additional 63,000 spectators expected to use the station during the 2012 Games [1-3]. Unlike London, the main public transport system during the 2010 World Cup in South Africa was a Bus Rapid Transit (BRT) System. The BRT had an integrated network of routes and corridors, with special stations and terminals to facilitate physical integration between trunk routes, feeder services, and other public transport systems [4-6]. In the case of Beijing, where 7-9 million attended the Olympic Games in 2008, the city had its established public transport system, including rail and bus systems. However, major upgrades were made to provide for the highly increased demand on public transport during the Olympics. Beijing doubled its operational subway lines to $190.64 \mathrm{~km}$, thus establishing a large network of rapid rail transit lines that operated during the Olympics [7-10]. Similar to these big events, the SMR line was designed to operate in specific days and in specific time periods. However, the line was required to operate with specific movement patterns between the Holy Sites of Mena, Muzdalifah and Arafat as shown in Figure 1. Accordingly, the line alignment, stations and operation were designed to accommodate the unusual demand volumes and movement patterns during the pilgrimage Season, which distinguishes the line from other rail lines, and makes it one of the most unique rapid transit systems in the world.

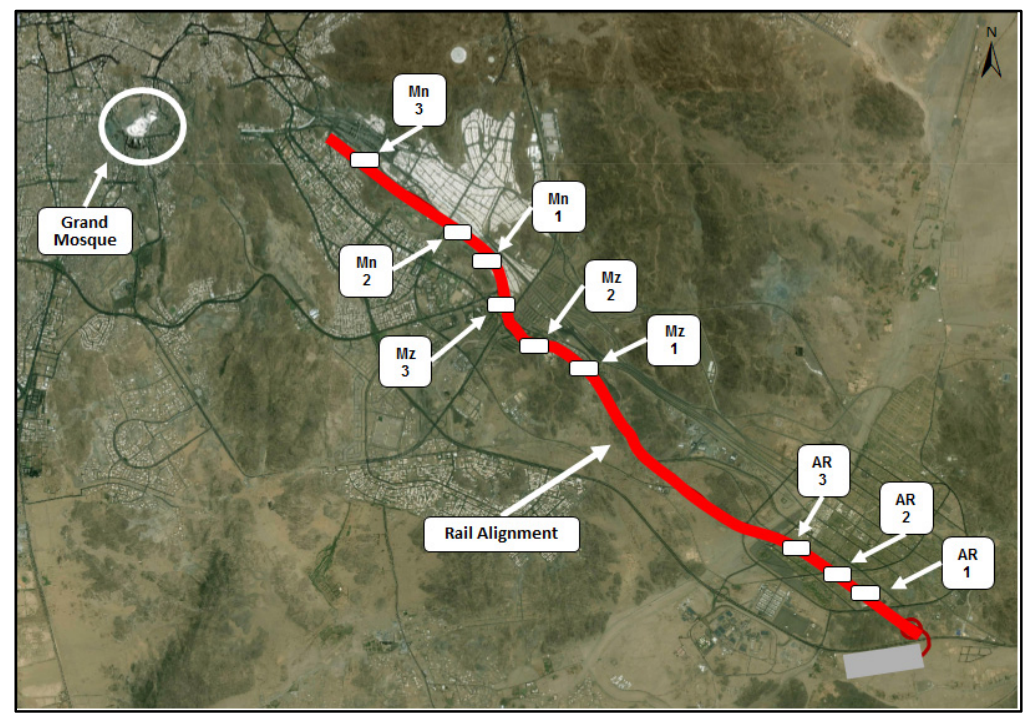

Figure 1: The Masha'er rail route. 


\section{Rail line characteristics}

As shown in Figure 1, the SMR line, with a length of $20 \mathrm{~km}$, consists of 9 stations ( 3 stations in each of Mena, Muzdalifah, and Arafat areas). The rail line tracks are elevated and extend over existing roads on a pier supported structure, with the piers constructed in the road median. The stations' design is relatively similar, with access to each station being accommodated by elevators, escalators, stairs, and ramps as shown in Figure 2. Outside the stations, waiting boxes were constructed using hard and movable fences in order to control the movement of pilgrims to stations during peak times. Furthermore, the platform area inside the stations was divided into two areas: a secondary waiting area and a boarding area, in order to control the movement of pilgrims in/out of the trains.

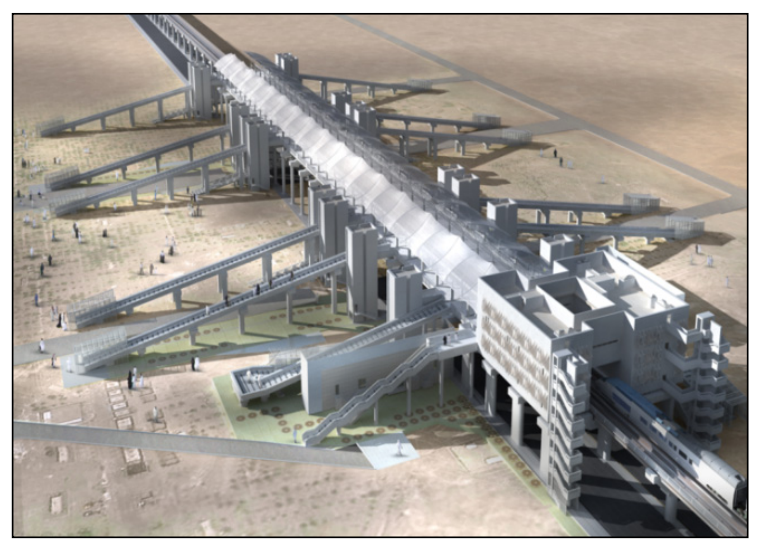

Figure 2: $\quad$ Station access.

Each train consists of 12 cars, with each train having a maximum capacity of 3,000 passengers. Each train has a length of $277 \mathrm{~m}$, and has 60 doors on each side ( 5 doors per car). In terms of expected ridership, only a limited number of pilgrims had access to the rail line during the 7 days of the pilgrimage season; they were recognized through bracelet tickets that were sold at the beginning of the pilgrims' journey, and were used as a proof of payment for using the rail line.

The rail line was designed to have 4 different operational strategies based on the pilgrimage rituals as follows:

- Movement A: regular rail operation on the 7th and 8th of Thul-Hijjah (the lunar month during which the pilgrimage takes place), with trains stopping at all stations (i.e. pilgrims were allowed to board and alight at all stations) as shown in Figure 3.

- Movement B: during parts of the 8th and 9th of Thul-Hijjah, trains were stopping only at Mena and Arafat stations to transport pilgrims from Mena stations to Arafat stations to perform Al-Tas'eed, as shown in Figure 4.

- Movement C: on the evening of the 9th of Thul-Hijjah, trains were stopping only at Arafat and Muzdalifah area stations to transport pilgrims from Arafat to Muzdalifah stations to perform Al-Ifadah, as shown in Figure 5. 


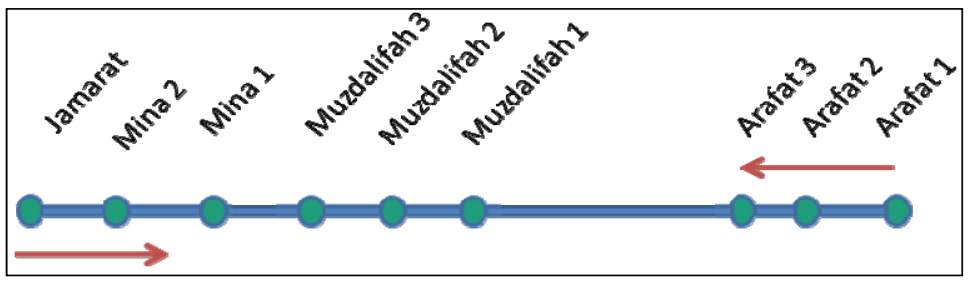

Figure 3: $\quad$ Train movement A.

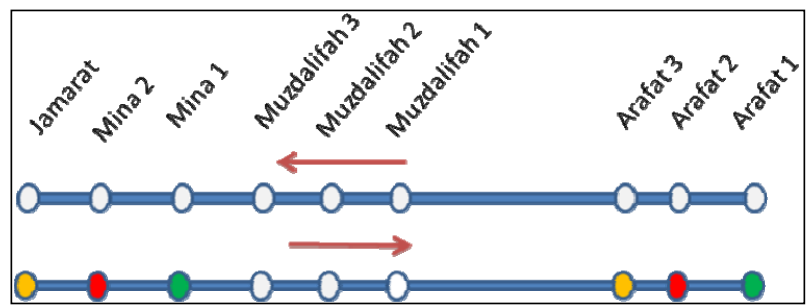

Figure 4: $\quad$ Train movement B.

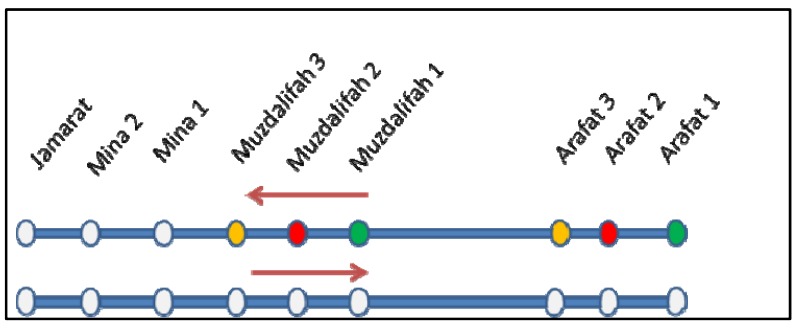

Figure 5: Train movement $\mathrm{C}$.

- Movement D: in the last four days of pilgrimage (10th to 13th of ThulHijjah, aka Al-Tashreeq days), trains were stopping only at Muzdalifah and Mena area stations to transport pilgrims from Muzdalifah to Mena stations to perform the stone-throwing ritual in Al-Jamarat as shown in Figure 6.

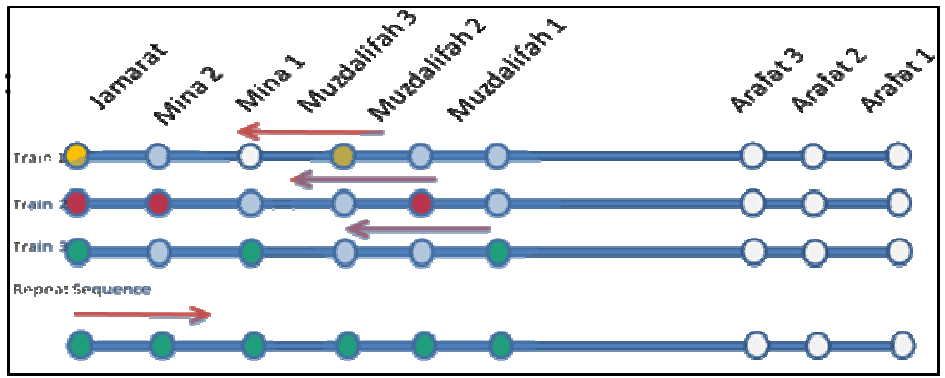

Figure 6: $\quad$ Train movement D. 


\section{Evaluation methodology}

The evaluation methodology consisted of the following tasks:

- Identifying the Performance Indicators (PIs) that will be used in the evaluation;

- Developing a data collection plan to collect the necessary data; and

- Data Analysis and Evaluation.

\subsection{Identifying the performance indicators}

A thorough review of case studies related to assessing the performance of rail systems revealed that rail performance assessment studies vary according to the system type, location, operation and context. After careful consideration, and given the unique nature of the SMR line, the study team proposed a set of PIs that were applicable in this case. In this paper, and due to the limited space available, we present the results related to the following PIs: train frequency; average flow on ramps; ridership (passenger volume) and offered capacity levels; average waiting time at stations (at different waiting areas); and users' expectations and evaluation.

\subsection{Data collection plan}

Three different teams (A, B and C) were assigned different tasks as follows:

- Team A, which consisted of 200 members, was responsible for conducting the rail users' survey, as well as recording GPS data of the train movements, and therefore had to stay inside the trains during the whole journey in order to interview pilgrims.

- Team B, which consisted of 103 members, was responsible for following groups of pilgrims while recording their own observations and opinion in a travel diary. This group also carried GPS loggers that recorded the members' movements.

- Team C1's mission was to perform counts of pilgrims accessing the stations.

- Team C2 was responsible for taking photos and videos.

During the data collection phase, on-the-ground engineers were supervising all groups to make sure that the groups were following the designated plan and carrying the right equipment. The second supervision task was performed during the data submission and storage, where at the end of each day, supervisors were collecting all the material such as filled questionnaires and traffic logs from the groups, and downloading and classifying the recorded GPS data. They also verified the compliance of the groups with the plan, and performed necessary modifications to the data collection process based on the problems faced by the students during the day. In terms of GPS loggers, the teams used the "HOLUX M-1000C Bluetooth GPS Logger". It can store up to 100,000 GPS points, and is sensitive to signals up to $-165 \mathrm{dBm}(\mathrm{dBm}$ is the power ratio in decibels $(\mathrm{dB})$ relative to one milliwatt). The device was configured during the data collection process to log one entry every two seconds. Unfortunately, several errors were encountered resulting from students misusing the GPS devices, turning off the 
devices, as well as other errors. Accordingly, specific measures were taken to overcome these problems and eliminate the induced errors. As for the users' questionnaire, 64 questions were included in the rail users' questionnaire: 6 demographic questions; 6 questions related to general aspects of the train experience; 23 questions related to comfort and density level; 26 questions related to rail operations; and 3 questions related to individual stations.

\section{Data analysis and evaluation}

As mentioned in the previous section, four types of data using different data collection tools were collected during the 2010 pilgrimage season to evaluate different aspects of the rail system operation and pilgrims' movement. In this section, we present some of the analysis results.

\subsection{Train frequency (Service Headway)}

As discussed earlier in this paper, the rail line was expected to operate at only $35 \%$ of its capacity in its first year of operation. However, the final published schedule of the line set the service headway at 10 min (i.e. a frequency of 6 trains per hour), implying that the line was supposed to operate at $25 \%$ of its capacity rather than $35 \%$ as initially planned. In order to analyse the extent to which the rail line adhered to the published schedule, the rail line frequency during the pilgrimage period is found using data gathered by GPS loggers. Due to space limitation, we present here the service frequency analysis related to movements $\mathrm{C}$ and D only.

Figure 7 shows the service frequency at Arafat stations on the evening of the $9^{\text {th }}$ of Thul-Hijjah (5-10 PM), which is the peak time for movement from Arafat to Muzdalifah (Movement C) when all pilgrims are required to leave Arafat to Muzdalifah before midnight. As shown in the figure, the rail line did not operate at the planned frequency of 6 trains per hour (i.e. 10 min headway), and operated at a frequency of 5 trains per hour for limited time periods only. During most time periods, in fact, the line operated with a service frequency of 4 trains per hour (i.e. $17 \%$ of the line maximum capacity), which is far below the planned $25 \%$ of the line's maximum capacity. One reason for this low service frequency is the coordination required at all stations, where trains departing from each of Arafat station are scheduled to arrive at their counterpart Muzdalifah stations, resulting in some delays at Arafat stations. Another reason is the limited time period at Arafat during which all pilgrims must leave Arafat, resulting in large crowds and long delays at Arafat stations.

Figure 8 shows the service frequency at Muzdalifah stations on the $10^{\text {th }}$ of Thul-Hijjah (Movement D). During the morning operating hours, the rail line did not operate at the planned frequency of 6 trains per hour. Not only that, but during most of the morning operating hours, the line operated with a service frequency of 3 or 2 trains per hour (i.e. $12.5 \%$ of the line maximum capacity), which is far below the planned $25 \%$ of the line's maximum capacity. During the 


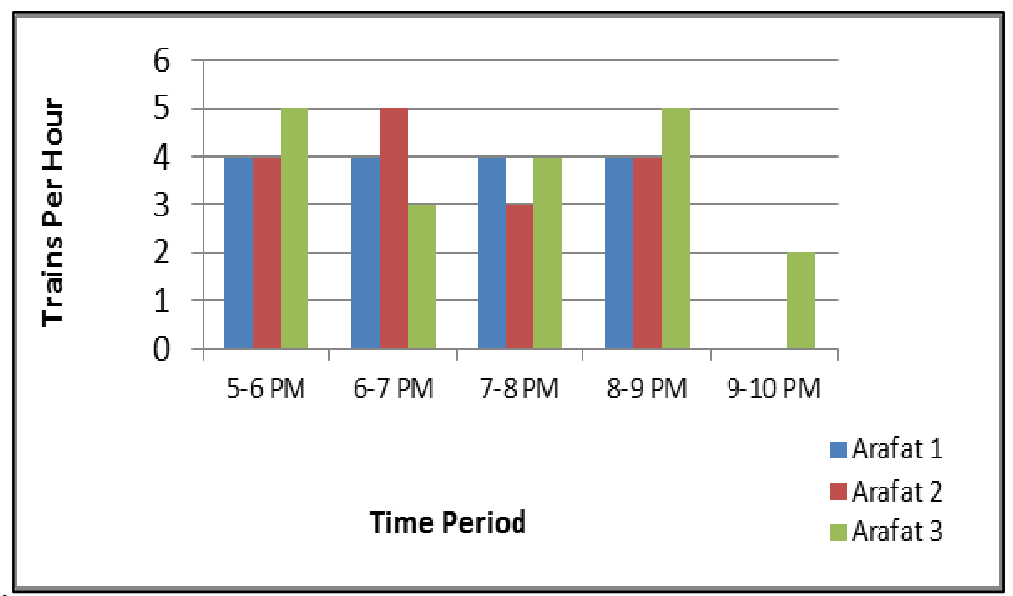

(a)

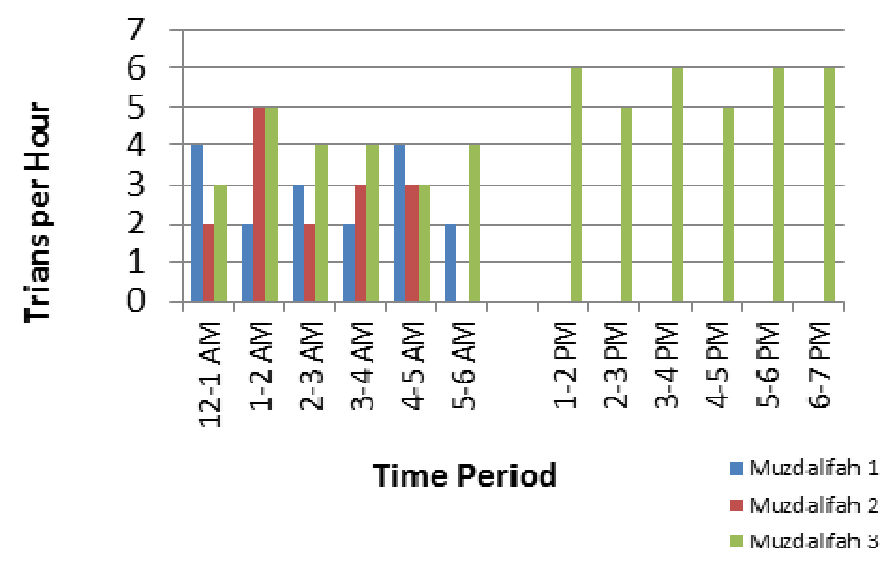

(b)

Figure 7: $\quad$ Line frequency (a) at Arafat Stations on the $9^{\text {th }}$ (b) at Muzdalifah Statins on the $10^{\text {th }}$.

afternoon and evening time period, however, the line operated at its planned capacity for most time periods (4 out of 6 hours), but only at Muzdalifah 3 station (the rail line did not operate at other Muzdalifah stations on that day). On the $11^{\text {th }}$ to the $13^{\text {th }}$ of Thul-Hijjah (Movement D), the rail line operated mostly according to schedule with a frequency of 5 or 6 trains per hour, albeit only at Muzdalifah 3 station. One reason for this improvement is related to the fact that trains were operating at Muzdalifah 3 station only, therefore eliminating the need 
to coordinate with trains at other Muzdalifah stations. Another reason is the reduction in the volume of pilgrims using the rail line during these three days at Muzdalifah stations, thus eliminating crowding at these stations

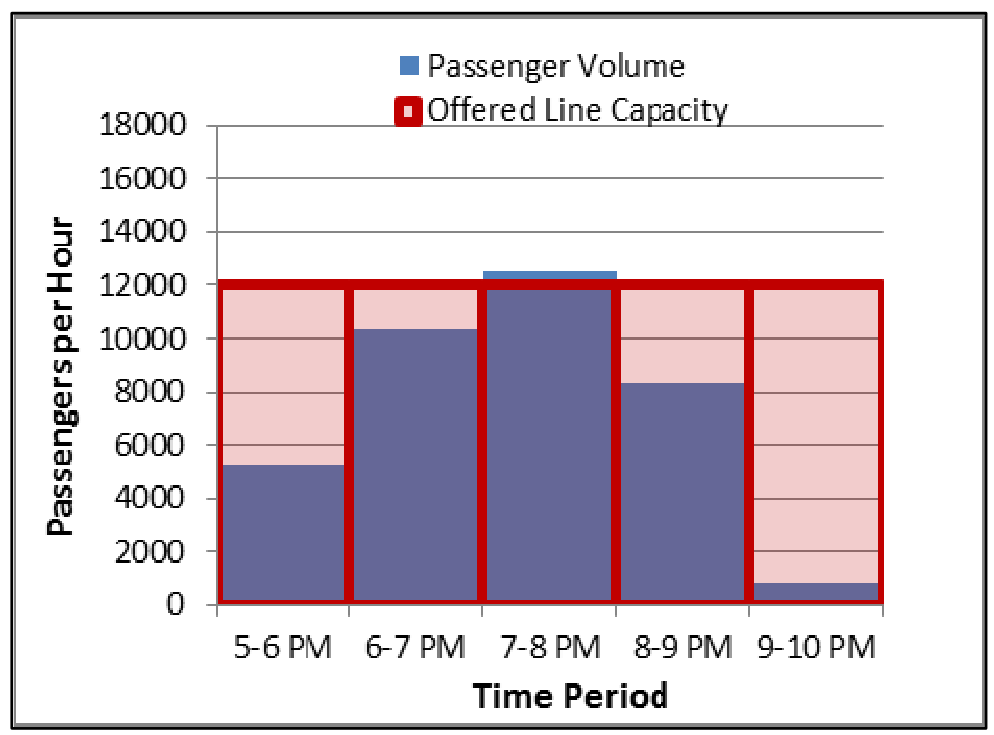

(a)

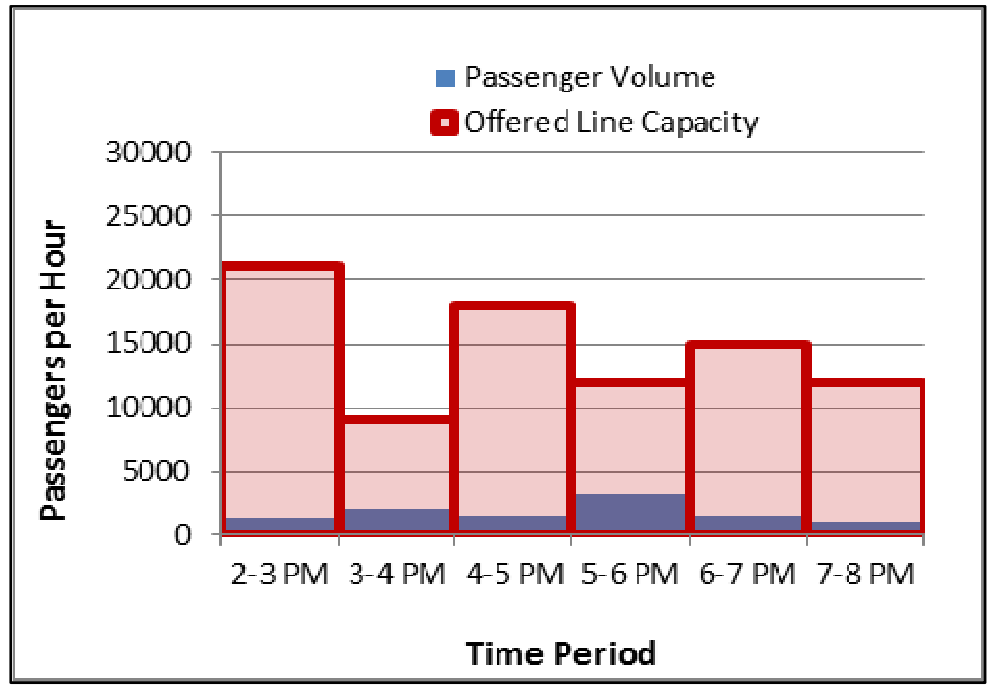

(b)

Figure 8: $\quad$ Volume and capacity (a) Arafat 1 Station on the $9^{\text {th }}$ (b) at Mena 3 Station on the $10^{\text {th }}$. 


\subsection{Passenger volume and offered capacity}

Although passenger counts were collected at only few stations and during limited time periods, these counts were used to obtain the passenger demand at these stations, and compare this demand to the offered capacity provided by the rail line. The collected data revealed that only a limited number of ramps and elevators, and none of the stairs or escalators, leading to the stations, were functional. Moreover, the data revealed that not all functional ramps were used by pilgrims to access the stations, which reflects the fact that pilgrims move in groups between their origin and destination and would normally choose the ramp closest to their origin/destination.

Figure 8a shows the passenger volume and offered line capacity at Arafat 1 station during the time period (5-10 PM) on the $9^{\text {th }}$ of Thul-Hijjah, which is the peak time for the movement of people from Arafat to Muzdalifah. As shown in the figure, the offered line capacity was consistent during the entire time period at 12,000 passengers per hour (i.e. 4 trains per hour). In terms of passenger volume at the station, the figure shows that the volume (i.e. demand) peaked during the 6-9 PM time period with an hourly volume of at least 8000 passengers per hour. Not only that, but during the 7-8 PM time period, the passenger volume actually exceeded the maximum offered line capacity, implying that some passengers experienced very long waiting times at Arafat 1 station. This is to be expected since, as mentioned earlier, all pilgrims are required to leave Arafat on the evening of the $9^{\text {th }}$, thus creating huge crowds at the station, and consequently, causing the passenger demand to exceed the maximum offered capacity of the line. However, if the line were to operate at its planned frequency of 6 trains per hour, then this problem would have been averted.

On the other hand, Figure $8 \mathrm{~b}$ shows the passenger volume and offered line capacity at Mena 3 station on the $10^{\text {th }}$ of Thul-Hijjah. As shown in the figure, the maximum offered line capacity ranged between 12,000 and 21,000 passengers per hour (i.e. between 4 and 7 trains per hour). The passenger volume at the station, however, was very low during this time period, with a maximum of close to 3,200 passengers per hour, resulting in a maximum utilized capacity of less than $27 \%$. These results imply that although the rail line was operating at less than $25 \%$ of its full capacity, the offered capacity exceeded the actual demand during certain time periods by a huge margin, illustrating poor capacity utilization and unnecessary extra operating costs. Although this low demand might be a result of the pilgrims' guidance program, which limits the number of pilgrims who are allowed to use the rail line, operation of the line in future years should be optimized to match the offered capacity to the expected passenger volume.

\subsection{Waiting times}

Table 1 presents the waiting times at stations (for each type of pilgrims' movement) extracted from the GPS loggers carried by Group B of the data collection team. 
Table 1: $\quad$ Waiting times at stations.

\begin{tabular}{|c|c|c|c|c|c|c|c|c|c|}
\hline $\begin{array}{c}\text { Origin } \\
\text { Station }\end{array}$ & $\begin{array}{c}\text { Mena } \\
1\end{array}$ & $\begin{array}{c}\text { Mena } \\
2\end{array}$ & $\begin{array}{c}\text { Mena } \\
3\end{array}$ & $\begin{array}{c}\text { Arafat } \\
1\end{array}$ & $\begin{array}{c}\text { Arafat } \\
2\end{array}$ & $\begin{array}{c}\text { Arafat } \\
3\end{array}$ & $\begin{array}{c}\text { Muz. } \\
1\end{array}$ & $\begin{array}{c}\text { Muz. } \\
2\end{array}$ & $\begin{array}{c}\text { Muz. } \\
3\end{array}$ \\
\hline $\begin{array}{c}\text { Destinatio } \\
\text { n Station }\end{array}$ & $\begin{array}{c}\text { Arafa } \\
\mathrm{t} 1\end{array}$ & $\begin{array}{c}\text { Arafa } \\
\mathrm{t} 2\end{array}$ & $\begin{array}{c}\text { Arafa } \\
\mathrm{t} 3\end{array}$ & $\begin{array}{c}\text { Muz. } \\
1\end{array}$ & $\begin{array}{c}\text { Muz. } \\
2\end{array}$ & $\begin{array}{c}\text { Muz. } \\
3\end{array}$ & $\begin{array}{c}\text { Mena } \\
1\end{array}$ & $\begin{array}{c}\text { Mena } \\
2\end{array}$ & $\begin{array}{c}\text { Mena } \\
3\end{array}$ \\
\hline $\begin{array}{c}\text { Average } \\
\text { Waiting } \\
\text { Time } \\
\text { (min) }\end{array}$ & 45 & 60 & 44 & 95 & 118 & 70 & 73 & 30 & 25 \\
\hline
\end{tabular}

The table shows that Arafat stations recorded the highest average waiting times among all the stations, with waiting times ranging between 70 and 118 minutes (it should be noted that this waiting time is calculated from the moment pilgrims arrive at the waiting boxes until they board the train). These very long waiting times are consistent with results of the passenger volume analysis, which showed that passenger demand exceeded the rail line's offered capacity during specific time periods at Arafat stations, implying that passengers had to wait for long periods of time to board the trains. Among other stations, Mena 2 and Muzdalifah 3 stations also recorded long average waiting times of 60 and 73 minutes respectively. On the other hand, the shortest waiting times were recorded at Muzdalifah 2 and 3 stations with average waiting times of 30 and 25 minutes, respectively.

\subsection{User evaluation and satisfaction}

A main component of this study involved conducting a rail users' survey, focusing on the users' profile, expectations, and satisfaction after using the rail system (in total, 1140 surveys were filled by the rail users). The majority of the interviewed users were males $(88.8 \%)$, and $5.4 \%$ were users with special needs or disabilities. The results revealed that about $70 \%$ of interviewed users were performing pilgrimage for the first time, whereas $28 \%$ of them had performed pilgrimage in past years. This result indicates that the majority of interviewed users had no previous pilgrimage experience, implying that they have no previous experience using the transportation system in the Holy Sites area to compare to their current experience using the SMR line. Several aspects of the pilgrims' experience were evaluated by the interviewed pilgrims. In this paper, we present the users' evaluation of access and egress times, waiting times and comfort levels, as well as their satisfaction with services and amenities and their satisfaction with the rail system in general. The results related to these aspects are as follows:

- $\quad$ Access and egress times: Overall, a small portion of users (less than 25\% at all stations) thought the time to reach and depart from stations was long, implying that the stations' access and egress times were acceptable for the majority of users, and that no major improvements to the flow program need to be made. This result also reflects the fact that pilgrims who used the rail system were located closest to the rail system stations in order to facilitate their movement to the stations. 
- Waiting times at the Waiting Boxes outside the stations: The majority of users evaluated the waiting time in the Waiting Boxes surrounding the stations as long or average. Arafat stations had the highest percentage of users, 50\%, who evaluated the waiting time as long, while Mena 3 station had the highest percentage of users, $20 \%$, who felt the waiting time was short.

- Waiting times at the Boarding Area: Average waiting times at Boarding Areas were reported by most users. Among all stations, Arafat stations had the most users, $79 \%$, who thought the waiting time is either average or long.

- $\quad$ Comfort level at the Waiting Boxes: Average comfort levels were reported by most of the pilgrims, with Arafat stations having the highest percentage of users, 31\%, who evaluated the Waiting Boxes as uncomfortable.

- Comfort level at the ramps: Average comfort levels were experienced by most of the pilgrims (more than $40 \%$ ) at entrance and exit of every station's ramps. Mena 3 station had the most pilgrims who felt that its ramps were uncomfortable at entrance and exit ( $32 \%$ and $27 \%$, respectively).

- $\quad$ Rail Line Services and Amenities: Cleanliness, safety, guidance panels, and employees' support were assessed by the rail line users. As shown in Figure 9 , more than $60 \%$ of users thought that all rail line services and amenities were excellent, and in particular $86 \%$ of users thought stations' cleanliness was good or excellent. On the other hand, $12 \%$ of users evaluated the guidance panels as bad, while less than $5 \%$ thought cleanliness and safety were bad. This implies that the services and amenities provided at stations are in good shape, and only minor improvements can be made in future years to improve upon the existing conditions/services at rail stations.

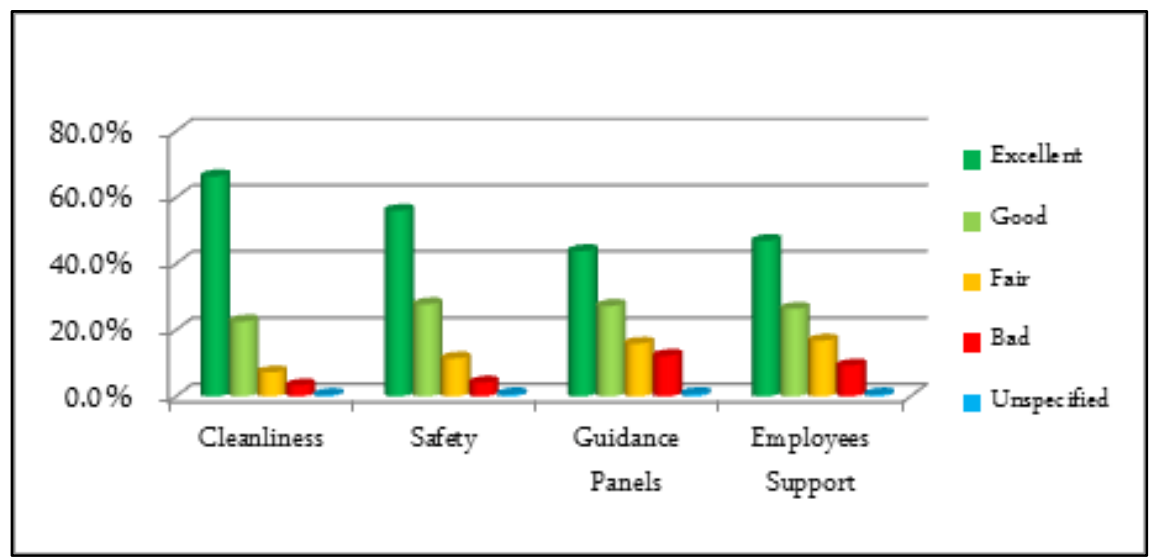

Figure 9: $\quad$ Services and amenities evaluation.

- $\quad$ Before and After Expectation and Satisfaction: Figure 10 compares the rail users' expectation before using the rail service and their satisfaction after using the service. As shown in the figure, most pilgrims thought that the rail 
line exceeded their expectations; whereas only $46 \%$ expected an excellent performance before using the rail line, $64 \%$ rated the rail as excellent after usage. More importantly, most of the pilgrim, $83 \%$, recommended using the rail in the future.

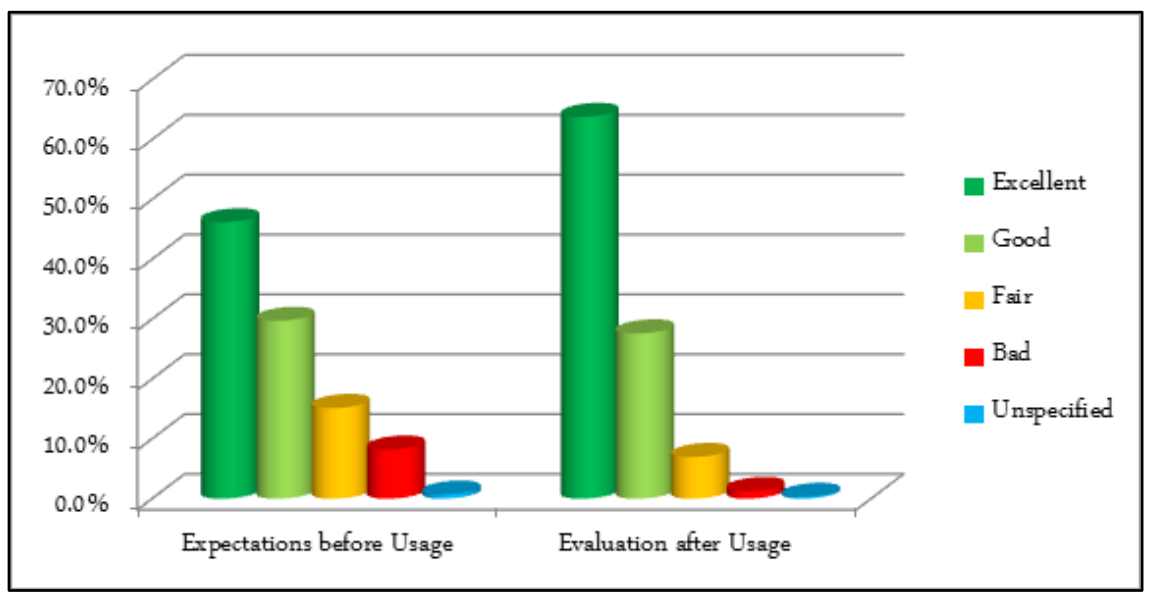

Figure 10: Before and after evaluation.

\section{Conclusions and recommendations}

It is evident that the SMR Rail line is a significant addition to the existing transport system in the Holy Sites area, and will introduce further improvements to the transport system once fully operational starting with the 2011 pilgrimage season. This is clearly illustrated in the survey results, which show that the majority of pilgrims found the rail line and its stations to be of excellent quality and recommended it as an alternate way of transportation to other pilgrims. This clearly demonstrates that even though the rail system may have faced some operational problems in its first year of operation, the majority of users were satisfied with its performance. Moreover, this is an encouraging sign that pilgrims understand the unique nature of this rail system and its operation, and that long waiting times can be expected at some stations. They also seem to realize that this is not necessarily a shortcoming of the rail system, but rather a result of the type of movements that occur during the pilgrimage season and the space and time constraints associated with these movements.

Nevertheless, the rail line faced some scheduling and operational problems during its first year of operation that resulted in fluctuations in service frequency that negatively impacted the overall punctuality and reliability of the system. In addition, with its limited operation, which in reality was significantly below the planned $35 \%$ of its full capacity, the rail line suffered from high density problems and long waiting times, specifically at Arafat stations, as well as inconsistent capacity utilization rates during the entire pilgrimage season. 
Accordingly, there are few issues that need to be addressed in future years to ensure that the SMR line operates with an acceptable level of service, better ontime performance, and better management of offered capacity, and also to ensure that that the pilgrims' movement program minimizes the access and waiting time for pilgrims and does not add further challenges to the operation of the rail line. Some of the most important recommendations are:

- Demand Management: It is recommended to synchronize the arrival pattern of pilgrims at stations with the rail line schedule in order to maximize the utilization of the rail system capacity (by ensuring that all trains make the best use of their capacity), and at the same time, minimize the waiting time of users at stations and their surrounding areas. This synchronization program should consist of measures that would enable the rail line operator to: manage passenger demand (i.e. control ridership level) in each time period during the pilgrimage season; manage passenger access to the station (by ensuring that all functional ramps, elevators, and escalators are used adequately); control boarding and alighting per station per time period; control train loading; and manage peak volumes and times by distributing the demand evenly over the time period available for each type of movement.

- $\quad$ Rail Operations: The analysis revealed that the operation of the rail line did not adhere to the planned schedule by the operator, and rarely operated at the planned frequency. Whether the proposed capacity was warranted or not (given the passenger volumes experienced at all stations), it is crucial that the rail line operates according to the planned schedule in order to maintain a reliable and consistent service, and to minimize the cases of long waiting times for passengers at stations. Furthermore, the analysis revealed that capacity utilization rates (passenger volume per hour compared to the offered capacity) were highly inconsistent, ranging from very low utilization rates (i.e. the offered capacity is significantly higher than the passenger volume) to utilization rates exceeding 1.0 (i.e. the offered capacity is less than the passenger demand). Even though this might be related to the fact that the demand was controlled during the first year of operation, controlling the demand to be very low diminished the main benefit of this rail line, which was supposed to be its ability to transport large volumes of pilgrims. This is a serious operational issue that needs to be dealt with in order to optimize the operations of the rail line by matching the offered capacity to the expected passenger demand. More specifically, more trains were needed at Arafat stations during the movement from Arafat to Muzdalifah (Movement $\mathrm{C}$ ) to accommodate the large number of people that need to be transported during a very short period of time, while less trains are needed during the movement from Muzdalifah to Mena (Movement D) as the movement of people is spread over a longer period of time each day. 


\section{Acknowledgements}

This research has been funded by the Center of Research Excellence in Hajj and Omrah (HajjCoRE), Umm Al-Qura University (KSA) under the project entitled "Assessing the Performance of the Southern Masha'er Rail Line in KSA during Hajj Season 1431H". The authors would also like to acknowledge the following people/institutions:

1- HajjCoRE for its critical support of the data collection needed to perform this research.

2- Dr. Habib Zain Al-Abideen, Undersecretary at the Ministry of Municipal and Rural Affairs and Supervisor General of the Ministry's Central Projects Administration, for all his support and cooperation.

3- Dr. Fadel Othman, Vice Dean of the Custodian of the Two Holy Mosques Institute of the Hajj Research, Umm Al-Qura University, for his general supervision.

4- All Hajj service agencies that positively contributed to the success of the research work.

\section{References}

[1] House of Commons Transport Committee. Transport for the London 2012 Olympic and Paralympic Games: The Draft Transport Plan: Olympic Delivery Authority Response to the Committee's Third Report of Session 2006-07”, 2007.

[2] House of Commons Transport Committee. Going for Gold: Transport for London's 2012 Olympic Games, Third Report of Session 2005-06, 2006.

[3] London Olympics Transport Upgrade, http://www.railwaytechnology.com/projects/london-olympics/

[4] Bus Rapid Transit System [BRT] and Road Safety, http://www.arrivealive.co.za/pages.aspx? $\mathrm{i}=2874$

[5] South Africa.info, http://www.safrica.info/business/economy/infrastructure/ transport.htm

[6] BBC News Website, http://www.bbc.co.uk/news/10259619

[7] Beijing Olympic Village Rail Link Construction, Railway-technology.com Web Site. http://www.railway-technology.com/projects/beijing-metro/

[8] Amos, A., Bullock, D., \& Sondhi, J., High-Speed Rail: The Fast Track to Economic Development?, The World Bank, 2010.

[9] J. Yukun, Analysis on Beijing Subway Flows during the 29th Olympics. Journal of Transportation, Systems Engineering and Information Technology, 8 (6), 2008.

[10] Mingjun, L., Baohua, M., Yu, H., Jianpeng, Z., \& C. Shaokuan. Comparison of Pre- \& Post-Olympic Traffic: A Case Study of Several Roads in Beijing. Journal of Transportation, Systems Engineering and Information Technology, 8 (6), 2008. 